Focus article

\title{
Hidden from Sight: Why the complexity of ME/CFS needs to be recognised by policy makers
}

\author{
Tomruk Ũstũnkaya ${ }^{1}$ and Richard Machin ${ }^{2 *}$ \\ 1 University of Surrey (ISC) \\ 2 Nottingham Trent University
}

\section{Background}

An estimated 260,000 people in the UK are living with Myalgic Encephalomyelitis/Chronic Fatigue Syndrome (ME/CFS); this neurological condition has been described as 'a serious, chronic, complex, and multisystem disease that frequently and dramatically limits the activities of affected patients' (Institute of Medicine, 2015). Despite this, there remains a lack of clarity about the diagnosis and treatment of ME/CFS. The authors of this paper refer to ME/CFS but recognise that other terms (for example systemic exertion intolerance disease, chronic fatigue immunity deficiency syndrome, and post-viral fatigue syndrome) are used to describe this neurological condition, and for some people these are preferred names. This paper adopts the definition of ME/CFS as a neurological condition of unknown origin as defined by the World Health Organisation and accepted by the UK Department of Health (WHO, n.d.).

The House of Commons debate which took place on 21 June 2018 will be taken as a significant starting point for the discussion on ME treatment and research; this is regarded as a key moment in the public debate and recognition of the condition stating that ME is 'a hidden illness' (Hansard HC Deb., 21 June 2018d).

Historically, there has been an emphasis on ME/CFS as being psychological in nature and this continues to exert a damaging influence on key areas of public policy. This paper considers the hidden nature of ME/CFS in relation to two particular issues: funding for research and social security policy. It is argued that medical research into the condition is impeded by a lack of adequate government funding. This is identified as critical in achieving a comprehensive health regime for sufferers. Social security is an important area of concern for ME/CFS suffers and a key policy area; correct entitlement to social security benefits is crucial for people with disabilities but appropriate access to welfare benefits is often obstructed by misunderstanding of the condition. It is argued that in both of these areas, a greater understanding of the impact of ME/CFS is required to allow policy makers and practitioners to more appropriately meet the needs of people living with the condition.

Copyright: (c) 2021, Author(s). This is an open access article distributed under the terms of the Creative Commons Attribution 4.0 License, which permits unrestricted use, distribution, and reproduction in any medium, provided the original author and source are credited. 


\section{ME/CFS: A concealed entity}

'The cruellest impact of ME is the fact that sufferers are not believed and that it is a hidden illness' (Hansard HC Deb., 21 June 2018d).

The effects of the condition can be incredibly debilitating and serious with some people experiencing the effects to a greater extent than others. Symptoms can include: post-exertional malaise or incapacitation, musculoskeletal pain, memory and concentration problems, headaches, flu-like symptoms (ME Association, 2020), and fast or irregular heartbeats (NHS, 2019). The degree of severity of the illness is categorised into 'mild', 'moderate' and 'severe' (NHS, 2019). The mild category sees patients able to perform daily tasks but with difficulty, those affected moderately may find completing daily tasks difficult, frequent resting may be necessary, problems with sleep may occur and a need to retract from work or education may be required. Patients affected severely could find it necessary to be housebound, bedbound or use a wheelchair, sensitivity may be experienced towards light and noise and recovery time following increased effort in daily activities could be prolonged. ME/CFS can impact the patients' quality of life to a great extent and a 'sufferer may experience on average greater disability than those with type 2 diabetes, congestive heart failure, back pain/sciatica, lung disease, osteoarthritis, multiple sclerosis and even most cancers' (Nacul et al., 2011). In the UK two people have been recorded as having died from ME/CFS (The ME Association, 2019).

In the Parliamentary debate on 21 June 2018 Carol Monaghan, MP, stated that the illness is "very much a hidden illness" which is 'misunderstood' (Hansard HC Deb., 21 June 2018d) and this paper supports the view that ME/CFS is hidden from sight and often unrecognised as a 'reality'. However, those with the condition must cope with the lived experience of the impact of their symptoms and daily challenges. Physical challenges and limitations on life ensue, and support networks can often struggle to fully understand the impact of the condition.

During the House of Commons debate, Conservative MP Alex Chalk stated that people with $\mathrm{ME}$ are not more susceptible to mental health or emotional problems, however they are "six times more likely to die by suicide" (Hansard HC Deb., 21 June 2018c). This is a very stark reality that underscores the importance of challenging the perceptions and treatment of the illness. This leads to considerations of funding research, discussed below.

\section{Funding for research}

The issue of funding for ME research was highlighted in the House of Commons: 'ME receives practically no biomedical research funding' (Hansard HC Deb., 21 June 2018a), meaning that funding is heavily reliant upon the charitable sector. Funding for biomedical research into ME/CFS has reduced from $£ 280,442$ in $2014 / 15$ to $£ 130,958$ in 2016/17 (Barber et al., 2018).

Sir David Amess MP, recognised that "Without that research, we simply will not be able to improve diagnosis or treatment for patients" (Hansard HC Deb., 24 January 2019b). Additionally, he called on the government "to consider properly funding the biomedical research that ME desperately needs" (Hansard HC Deb., 24 January 2019b). This paper argues that medical professionals can only work with the resources they are able to secure and therefore require the support of the government. Funding would support medical professionals enabling them to carry out further research into treatments to ultimately find a cure. Supporting the medical profession is a paramount 
consideration, and without adequate funding, the misunderstandings relating to the disease will be prolonged.

The $£ 5$ million clinical PACE trials examined the effectiveness of non-drug treatments, including graded exercise therapy (GET), cognitive behavioural therapy (CBT) and adaptive pacing therapy (APT) (Sharpe et al., 2019). Significant concerns have been raised about the trials and medical treatments available to ME/CFS patients. These concerns have been echoed in political debate: 'Patients with ME feel that they have been let down time and again as research such as the PACE trial... have been found to be seriously flawed' (Hansard HC Deb., 21 June 2018e). A subsequent House of Commons debate stated 'CBT is not a cure or a treatment. It may help some people cope with the depression and mental health issues that come from being so disabled, but it does not tackle the underlying ME' (Hansard HC Deb., 24 January 2019c).

Further research is required to find more suitable treatments for ME/CFS patients, particularly as 'the parameters for recovery were changed midway through the trial' (Hansard HC Deb., 21 June 2018a). The position of insurers and the Department for Work and Pensions (DWP) is concerning as the PACE trial was partly funded by the DWP: 'links of some of its main authors to health insurance companies are troubling' (Hansard HC Deb., 21 June 2018b). Concerns were raised about children enduring 'life changing disabilities' as a consequence of GET. Additionally, it has been asserted that GET 'can actually make things much worse' (Hansard HC Deb., 24 January 2019c). Updated NICE guidelines were expected to be published on $18^{\text {th }}$ August 2021, although this has been paused.

\section{ME/CFS and Social Security}

Carol Monaghan MP, stated that "ignorance surrounding the condition makes it harder for people to access benefits, and assessors from the Department for Work and Pensions often decide that sufferers are fit for work". (Hansard HC Deb., 24 January 2019a). This section of the paper focuses on the ways in which ME/CFS can lead to entitlement to Personal Independence Payment (PIP) and Employment Support Allowance (ESA) and the challenges that are often evident for claimants. The analysis is underpinned with reference to leading case law in this area.

PIP was introduced in April 2013 and serves as the main non-means tested disability benefit for working age claimants in the UK (Machin, 2017). Replacing Disability Living Allowance (DLA), PIP is designed to provide financial support to meet the additional costs associated with long-term disability and health conditions. PIP places an emphasis on limited ability to carry out a range of 10 daily living activities and two mobility activities, it has two components (daily living and mobility) and a claimant may be awarded one or both of these elements. 1

Ostensibly, the position for ME/CFS claimants is no different from claimants with other conditions as an award of PIP is based on needs resulting from a disability or longterm health condition relating to physical, mental, cognitive, or sensory impairments. However, particular challenges are evident.

PIP decision-making and completion of the claim form: ME/CFS has a range of physical, mental, and cognitive symptoms. When considering if ME/CFS will lead to entitlement to PIP this can unnecessarily complicate the decision-making process as the care and mobility needs of the claimant should be the principle consideration and not the condition itself. It follows that in many cases there will be an overlap between various physical and mental health symptoms which have a significant cumulative impact. Case law $\underline{2}$ indicates that a claimant who suffered from CFS and fibromyalgia argued that the 
cumulative impact of pain and exhaustion prevented him from undertaking a range of tasks including preparing a cooked main meal.

A further case ${ }^{3}$ demonstrates that entitlement to PIP should focus on the impact of impairment, not the impairment itself. It was held that the ways in which a claimant compensates for impaired function is not defined in the PIP regulations, and a claimant who suffering from fatigue is entitled to use any 'device' to assist with care needs. Devices that a claimant may use include a perching chair, an ordinary chair, a wheelchair, a shower stool, or a bed.

Claimants with ME/CFS may also face challenges recording the complexity of their needs on the PIP claim form and experience issues during the medical assessment for the benefit. An inquiry by the House of Commons Work and Pensions Committee (2018) found that claimants with non-visible health conditions felt that their care and mobility needs were often overlooked, and that assessors often fail to appropriately take account of fluctuating conditions.

Pybus et al (2019) analysed nearly 150,000 PIP claims for mental health claimants and over 175,000 claims for non-psychiatric disorders. They found that claimants transferring from DLA to PIP who have a mental health problem are 2.4 times more likely to lose entitlement than those with physical health problems. This can be a particular issue for ME/CFS claimants if PIP decision-makers erroneously focus on a psychological derivation for the condition.

The PIP qualifying period and fluctuating conditions: entitlement to PIP rests on the claimant having a long-term condition. This requires the claimant to have met the conditions of entitlement for three months prior to the claim and be reasonably expected to meet the conditions for a further nine months. Points can be awarded to a claimant if their condition affects their ability to complete a daily living or mobility activity in 50 per cent of the days within this 12-month qualifying period. Although the intention is for PIP to make a more objective assessment of need, issues can clearly arise for claimants with conditions such as ME/CFS as a more 'arithmetical approach' is adopted compared to the previous DLA assessment regime. Case law held 4 that a 'broad brush approach' to determining a pattern of need, as established in the leading DLA judgment made by the House of Lords (Moyna v Secretary of State for Work and Pensions) should not be extended to PIP claimants.

Furthermore, where a claimant is awaiting treatment and there is a lack of certainty about its impact, the decision maker should allow for the choice of activities as though the treatment has not been secured. If a claimant is unable to perform a daily living or mobility activity until medication has taken affect, then they should be judged as having limited ability to complete the activity. Given the uncertainties around diagnosis and treatment of ME/CFS described in the previous section of the paper, this is a crucial consideration.

Completing activities reliably, repeatedly and in a reasonable time: A critical consideration for people with ME/CFS who are seeking to claim PIP is the question of 'reasonableness' when completing an activity. Again, the hidden nature of the condition can impede accurate decision-making. Decision-makers should consider whether a claimant can complete an activity in a reasonable time; that is no more than twice as long as non-disabled person would take to complete the same activity.

In considering the question of repeated tasks, a decision-maker should take a common-sense approach. For example, it is to be assumed that everyone needs to get in and out of bed, wash and dress and take three meals a day. For claimants with $\mathrm{ME} / \mathrm{CFS}$ consideration should be given as to whether there are activities that need to be 
performed more regularly than a non-disabled person, the impact of the exertion of completing a task, and the assistance required from another person.

A number of legal decisions are of relevance to ME/CFS. It has been found 5 that that when considering if an activity can be completed safely, it is not necessary to show that the occurrence of harm was 'more likely that not'. If for the majority of days, the claimant was unable to carry out an activity safely then the relevant PIP descriptor should be applied. The relationship between repeatedly, a reasonable time and acceptable standard has been considered, and it was held $\underline{6}$ that the ability to mobilise to an acceptable standard must take into account the effects of pain.

\section{Employment and Support Allowance}

ESA is the main UK social security benefit for working-age claimants who are unable to work due to illness or disability. There are two types of ESA: contribution-based ESA, which is referred to as 'New style Employment and Allowance', and income-related ESA, which is in the process of being replaced by Universal Credit. Entitlement to ESA is determined by a functional assessment of need called the Work Capability Assessment (WCA) (Department for Work and Pensions, 2019).. The WCA sets out a range of ten physical activities and eight mental, cognitive, and intellectual activities which a claimant should reasonably be expected to undertake in the workplace.

In 2012, amendments were made to the ESA Regulations 2008; of significance to claimants with ME/CFS was the clarification that physical descriptors should only apply to claimants with physical health problems and mental health descriptors only have applicability to claimants with mental health problems. The intention behind these amendments was to provide clarity for claimants and decision makers but for ME/CFS patients this may seem a false distinction for such a complex condition. Despite this, the WCA handbook states that the mental health descriptors should be considered "where there is evidence of a physical or sensory disability such as tinnitus or Chronic Fatigue that may impact on mental function' and this is recognition of significance and something for ME/CFS advocates to pursue.

For potential ESA claims for people with ME/CFS, careful consideration needs to be given to what constitutes the 'majority of time', regulations 34 (2) of the 2008 Employment and Support Act states:

"A descriptor applies to a claimant if that descriptor applies to the claimant for the majority of the time or, as the case may be, on the majority of the occasions on which the claimant undertakes or attempts to undertake the activity described by that descriptor".

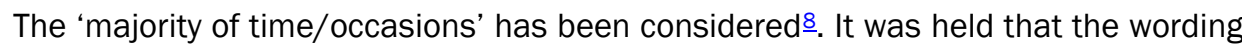
of individual ESA descriptors should not override the regulations; the regulations should be interpreted as a 'coherent whole'.

Some specific ESA activities highlight important issues for ME/CFS claimants:

- Activity 1, Mobilising: This activity considers the distance over which a claimant can mobilise on level ground. This is effectively a test of lower limb function, but the effects of fatigue should be considered. Consideration should be given as to whether a claimant can repeat the activity within a reasonable time; comparison with a person without an impairment should be made. When judging the distance that a claimant can mobilise, the maximum distance should be when they cannot proceed any further due to fatigue. 
- Activity 6, Making self understood through speaking, writing, typing, or other means which are normally, or could reasonably be, used, unaided by another person: This activity considers the ability of a claimant to express themselves. The WCA handbook states that speech is 'an extremely complex activity, involving intellectual, neurological and musculoskeletal components' and that speech for claimants with CFS may become unclear.

- Activity 13, Initiating and completing personal action: The WCA handbook stipulates that this activity considers the ability to initiate and complete tasks without prompting and that mental fatigue may be a factor. Activities, which a decision-maker should consider, include dealing with simple household tasks, planning appointments, dealing with finances, and making travel arrangements.

The reality for many ME/CFS claimants is that the complexity of their symptoms may not easily be aligned with the prescriptive nature of the ESA regulations. The experience of many advisers from the social welfare sector is that the amendments made to the ESA regulations over the last decade have made it more difficult for claimants to score the required 15 points or more under the WCA.

For this reason, consideration should be given to the applicability of the exceptional circumstances regulations. .9 The WCA handbook states that the policy intent behind this regulation is to recognise the exceptional circumstances of claimants whose functional ability may appear to be satisfactory when using the WCA point system as the benchmark, but nevertheless a substantial risk or harm would present if they were to be found fit for work. The substantial risk can be for the claimant themselves or for a third party; a judgment should be made as to whether reasonable adjustments in the workplace or medication could ameliorate the risk.

Of relevance to ME/CFS claimants, it was held 10 that if pain was to be experienced on an increasingly regular basis then this could amount to substantial harm. The Court of Appeal11 set out some useful considerations which ME/CFS advocates should be familiar with when considering the substantial risk argument. It was held that a substantial risk may be posed to the claimant if they are not found to have limited capability for work and are, therefore, required to sign on as available for work and claim Job Seekers Allowance. Additionally, the substantial risk that may be posed to the claimant should be considered in the context of the work that the claimant would be likely to secure and not any work. Finally, and of particular relevance to ME/CFS claimants, it was held that when considering substantial risk associated with work it is not only the duties of a job that should be considered. Factors such as the ability to appropriately prepare for work and to travel to the workplace are equally relevant.

The problems with the benefit system experienced by people with ME/CFS have been exacerbated by the COVID-19 pandemic. People with ME/CFS are classified as a vulnerable group as COVID-19 is likely to cause a worsening or relapse of conditions (ME Association, 2020). During the first COVID-19 lockdown in the UK, there was a reduction in the numbers of people claiming disability benefits such as PIP. Concerns have been expressed about a lack of support for disabled claimants with accessing support and obtaining medical evidence (Machin, 2021). Similarly, the suspension of face-to-face medicals as part of the disability benefits decision-making process can place additional burdens on claimants with conditions such as ME/CFS, who must articulate complex needs over the phone or online. Claimants who are refused a social security benefit can pursue an appeal to a tribunal. However, during the COVID-19 pandemic these can be heard remotely via telephone. Burton (2021) expresses concern that remote hearings impair access to justice, are difficult for unpresented claimants to manage and can impede the provision of witness evidence. People with ME/CFS often found themselves marginalised by the benefit system in pre-pandemic times. The new arrangements for 
benefit medicals and tribunal must be monitored to ensure that this exclusion is not worsened.

\section{Conclusion}

Clarity is paramount to bring ME/CFS out from the 'invisible' sphere in terms of both the treatment and definitions of the illness, and the ways in which the condition is understood by government departments, institutions, and society. This clarity will be difficult to attain without adequate funding for research into the illness and may explain the ongoing preference for psychological treatments. The emergence of post-COVID syndrome (long-COVID) has emphasised how important it is to appropriately fund research into long-term and debilitating conditions. Interestingly, the Department for Work and Pensions have issued new guidance stating that children suffering with postCOVID syndrome can be awarded disability benefit for a period of 12 months (DWP, 2021); this has provided the type of clarity that is lacking for ME/CFS patients. The authors of this paper recognise the challenges that a lack of funding presents for the treatment of the condition and are supportive of the medical profession and the on-going medical support provided to ME/CFS patients.

For those members of society with greatly reduced quality of lives due to the challenges presented by ME/CFS, it is clear that public policy and bureaucratic decisionmaking processes must respond more appropriately to their needs. Positive government intervention is necessary to end the uncertainty for ME/CFS patients. The human cost of policy failure for people with ME/CFS is paramount; however, the financial costs are also significant. A study estimated that the total cost of ME/CFS to the UK economy is $£ 3.3$ billion per year, or only $£ 16,966$ per person living with the condition (Hunter et al., 2017). These figures underscore the importance of providing adequate funding for treatment and a functioning social security safety net.

Until the WHO classification of ME/CFS as a neurological condition is fully recognised by policy makers, we will continue to see challenges for patients, not only in terms of funding for treatment and social security which have been examined in this paper, but across the full spectrum of public policy. ME/CFS patients experience 'multiple pathophysiological changes that affect multiple systems' (Centers for Disease Control, 2018). Policy makers must recognise the severity of the condition to make appropriate responses to it.

The hidden nature of this condition can be linked to an absence of a biomarker and because uncertainty surrounds it medically and in society. However, this should not mean that the needs of ME/CFS patients are overlooked or marginalised; the challenges presented by the condition are a reality for patients and their families. Patients are entitled to expect appropriate support from the Department of Health, Department for Work and Pensions, employers, and educational establishments. The words of Alex Chalk, MP, (Hansard HC Deb., 21 June 2018c) offer hope for a future characterised by a determined, active effort to help "I conclude by paying tribute to the silent sufferers of this cruel disease in our country. Let the word go out from the House of Commons: they shall be silent no longer". 


\section{Notes}

1 Parts 2 and 3 of schedule 1 to the Personal Independence Payment Regulations 2013 (PIP Activities)

2 MM v Secretary of State for Work and Pensions [2018] UKUT 93 (AAC)

3 NA v Secretary of State [2015] UKUT 0572)

4 JC v Secretary of State for Work and Pensions - [2015] UKUT 0144 (AAC) CSPIP/754/2014

5 RJ, GMcL and CS v Secretary of State for Work and Pensions v RJ (PIP): [2017] UKUT 105 (AAC); [2017] AACR 32

6 PS v SSWP [2016] UKUT 0326 (AAC)

7 Schedule 2 of the Employment and Support Allowance Regulations 2008, and Schedule 6 of the Universal Credit Regulations 2013

8 CH v Secretary of State for Work and Pensions (ESA) [2013] UKUT 0207 (AAC)

9 Regulation 29 (2) (b) and regulation 35 (2) of the Employment and Support Allowance Regulations 2008, as amended by the Universal Credit and Miscellaneous Amendment Regulations 2014

10 JW v SSWP (ESA) [2011] UKUT 416 (AAC)

11 Charlton v SSWP [2009] EWCA Civ 4

*Correspondence address: Richard Machin, Nottingham Trent University, Room: 3218 Chaucer Building, Social Work, Care and Community - School of Social Sciences, Nottingham Trent University, 50 Shakespeare Street, Nottingham NG1 4FQ. Email: Richard.machin@ntu.ac.uk.

\section{References}

Barber, S., Sutherland, S. and Harker, R. (2018) Myalgic Encephalomyelitis treatment and research. Available at: https://commonslibrary.parliament.uk/researchbriefings/cdp-2018-0155/ [Accessed: 31/03/2019]

Burton, M. (2021) Remote hearings in the social security tribunal: should we be worried? Journal of Social Security Law, 28, 1, 36-53.

Centers for Disease Control (2018) Myalgic Encephalomyelitis/Chronic Fatigue Syndrome. Available at https://www.cdc.gov/me-cfs/healthcareproviders/presentation-clinical-course/etiology-pathophysiology.html [Accessed: 10/04/2021]

Department for Work and Pensions (2019) Work Capability Assessment (WCA) Handbook. London: Department for Work and Pensions. Available at: https://assets.publishing.service.gov.uk/government/uploads/system/uploads/a ttachment_data/file/777221/wca-handbook.pdf [Accessed: 21/11/2019]

Department for Work and Pensions (2021) Medical guidance for DLA and AA decision makers (child cases): Staff guide. London: Department for Work and Pensions. Available https://assets.publishing.service.gov.uk/government/uploads/system/uploads/a ttachment data/file/976137/a-z-child-medical-conditions.pdf [Accessed: 14/06/2021] 
Hansard (2018a) HC Debate, vol 643, col 190, 21 June 2018.

Hansard (2018b) HC Debate, vol 643, col 191, 21 June 2018.

Hansard (2018c) HC Debate, vol 643, col 203, 21 June 2018.

Hansard (2018d) HC Debate, vol 643, col 207, 21 June 2018.

Hansard (2018e) HC Debate, vol 643, col 224, 21 June 2018.

Hansard (2019a) HC Debate, vol 653, col 421, 24 January 2019.

Hansard (2019b) HC Debate, vol 653, col 425, 24 January 2019.

Hansard (2019c) HC Debate, vol 653, col 440, 24 January 2019.

House of Commons Work and Pensions Committee (2018) PIP and ESA assessments. Seventh report of the session 2017-19 (HC 829). Available at: https://publications.parliament.uk/pa/cm201719/cmselect/cmworpen/829/82 9.pdf [Accessed: 21/11/2019]

Hunter, R., James, M. and Paxman, J. (2017) Counting the Cost. Chronic Fatigue Syndrome/ Myalgic Encephalomyelitis. Available at: https://meassociation.org.uk/wp-content/uploads/2020Health-Counting-theCost-Sept-2017.pdf [Accessed: 10/04/2021]

Institute of Medicine (2015) Beyond myalgic encephalomyelitis/chronic fatigue syndrome: Redefining an illness. Washington, DC: The National Academies Press.

Machin, R. (2017) Made to measure? An analysis of the transition from Disability Living Allowance to Personal Independence Payment. Journal of Social Welfare and Family Law, 39, 4, 435-453. DOI: 10.1080/09649069.2017.1390291

Machin, R. (2021) COVID-19 and the temporary transformation of the UK social security system. Critical Social Policy, February 2021. DOI:10.1177/0261018320986793

ME Association (2020) ME Association Guidance: Reducing the risk of Covid-19 and PVFS/ME/CFS I 19 May 2020. Available at: https://meassociation.org.uk/2020/05/me-association-guidance-reducing-therisk-of-covid-19-and-pvfs-me-cfs-19-may-2020/ [Accessed: 10/04/2021]

Nacul, L.C., Lacerda, E.M., Campion, P., Pheby, D., de L Drachler, M., Leite, J., Poland, F., Howe, A., Fayyaz, S. and Molokhia, M. (2011) The functional status and well being of people with myalgic encephalomyelitis/chronic fatigue syndrome and their carers. BMC Public Health, 11, 402. Available at: https://doi.org/10.1186/14712458-11-402

NHS UK (2019). Symptoms - Chronic fatigue syndrome (CFS/ME). Available at: https://www.nhs.uk/conditions/chronic-fatigue-syndrome-cfs/symptoms/ [Accessed: 31/03 /2019]

Pybus, K., Pickett, K., Prady, S., Lloyd, C. and Wilkinson, R. (2019) Discrediting experiences: Outcomes of eligibility assessments for claimants with psychiatric compared to non-psychiatric conditions transferring to Personal Independence Payments in England. BJPsych Open, 5, 2, E27.

Sharpe, M., Goldsmith, K. and Chalder, T. (2019) The PACE trial of treatments for chronic fatigue syndrome: a response to WILSHIRE et al. BMC Psychol, 7, 15.

The ME Association (2019) ME Awareness: 'My daughter, 21, who died weighing $51 / 2$ stone, had ME on her death certificate - yet some still say it's not real'. Available at: https://meassociation.org.uk/2019/05/me-awareness-my-daughter-21-whodied-weighing-five-and-a-half-stone-had-me-on-her-death-certificate-yet-some-stillsay-its-not-real-06-may-2019/ [Accessed: 08/11/2021].

WHO (n.d.) WHO classification of diseases, ICD-10, Ref G93.3. Available at: ICD-10 Version:2016 (who.int) [Accessed: 21/11/2019] 